\title{
CARACTERÍSTICAS DAS RESIDÊNCIAS E DO MICROAMBIENTE NA CIDADE DE ITUVERAVA/SP
}

\author{
LIPORACI, Tales de Paula Checchia ${ }^{1}$ \\ CAMPOS, Aline Gomes de ${ }^{2}$ \\ TERRA, Sílvia Azevedo ${ }^{3}$
}

Recebido em: 2009.12.12

Aprovado em: 2010.02 .22

ISSUE DOI: $10.3738 / 1982.2278-333$

\begin{abstract}
RESUMO: Vários fenômenos alérgicos que acometem o homem podem ser decorrentes do contato com ácaros de poeira domiciliar que são encontrados em residências, as quais disponibilizam nutrição e temperatura e umidade adequadas ao seu desenvolvimento. O objetivo deste estudo foi caracterizar o ambiente (sala, quarto de casal e quarto de solteiro) e o microambiente (sofá, cama de casal e cama de solteiro) de acordo com suas características físicas, além de quantificar a quantidade de ácaros por grama de poeira. Foram selecionadas aleatoriamente 30 residências, onde foram coletadas amostras de poeira domiciliar dos microambientes selecionados. Os proprietários dos domicílios assinaram um Termo de Consentimento e responderam a um questionário sobre as características da residência. No momento da coleta da poeira domiciliar aferiu-se a temperatura e a umidade relativa do ar. As residências de alvenaria, com mais de 10 anos e piso de cerâmica foram a maioria no estudo, onde a frequiência de limpeza semanal com varredura e pano úmido foi a mais utilizada, sendo o microambiente da cama de solteiro o que possuía maior número de ácaros por grama de poeira. Sendo assim, a freqüência de limpeza deve ser mais cuidadosa nos microambientes dos moradores portadores de alergia.
\end{abstract}

Palavras-chave: Ácaros de poeira domiciliar. Microambiente. Alergia.

\section{CHARACTERISTICS OF THE HOME AND THE CITY OF MICROENVIRONMENT ITUVERAVA / SP}

\begin{abstract}
SUMMARY: Several allergic phenomena that affect humans can be caused by contact with dust mites that are found in homes, which provide nutrition and temperature and humidity for its development. The objective of this study was to characterize the environment (room, double room and single room) and microenvironment (sofa bed and single bed) according to their physical characteristics, and quantify the amount of mites per gram of dust . 30 randomly selected households, where they were collected house dust samples from selected microenvironments. The owners of homes have signed a consent form and answered a questionnaire about the characteristics of the residence. At the time of collection of dust was measured in the temperature and relative humidity. The homes of masonry with over 10 years and tile floors were the most in the study, where the frequency of weekly cleaning with a damp cloth and sweep was the most used, and the microenvironment of the single bed that had the largest number of mites per gram of dust. Thus, the frequency of cleaning should be more careful in the microenvironments of residents suffering from allergy.
\end{abstract}

Keywords: House dust mites. Microenvironments. Allergy.

\footnotetext{
${ }^{1}$ Biólogo pela Faculdade de Filosofia, Ciências e Letras/FE (FFCL/FE)

${ }^{2}$ Bióloga - Mestranda em Patologia Geral pela Universidade Federal do Triângulo Mineiro (UFTM)

${ }^{3}$ Professora Doutora do Curso de Medicina Veterinária da Faculdade Dr. Francisco Maeda/FE (FAFRAM/FE) in memorian
} 


\section{INTRODUÇÃO}

A alergia é um estado de hipersensibilidade imunologicamente mediada que resulta da exposição a um alérgeno, o qual é uma substância biológica ou química que causa reações alérgicas (TAKETOMI; SOUZA, 1998). Segundo Gell e Coombs (1975), a hipersensibilidade do tipo I ou imediata é o tipo mais freqüente e compreende diversas alterações atópicas como asma, rinite, dermatite atópica, conjuntivite, urticária e reações anafiláticas.

Medeiros Júnior et al. (1997) relataram que os antígenos inaláveis são os mais importantes agentes etiológicos da atopia, dentre os quais destacam-se pólens, fungos, poeira domiciliar, ácaros de poeira domiciliar e de estocagem, baratas e epitélio de animais.

A maior parte (2/3) dos fenômenos alérgicos respiratórios do homem são decorrentes não só de ácaros ambientais, como também de seus restos corpóreos e de seus dejetos deixados no ambiente onde o homem habita ou trabalha (BAGGIO, 1989).

Os ácaros de poeira domiciliar são encontrados nas residências, em locais onde se nidificam e reproduzem com facilidade, como travesseiros, colchões, almofadas, tapetes, carpetes, móveis, estofados, roupas de cama, entre outros, desde que estes ambientes ofereçam boas condições ambientais de umidade, temperatura e alimentação. A poeira domiciliar é a camada de partículas suspensas no ar ou que se sedimentam, cobrindo pisos e prateleiras e também aquela que penetrou em colchões, móveis, estofados, carpetes, e outros, e em sua composição encontram-se fibras de algodão, lã, descamação da pele humana e de animais, cinzas, pedaços de unhas, fragmentos de pêlos e penas, partículas resultantes do uso normal da casa, grãos de pólen, migalhas de alimentos, etc... (FLECHTMANN, 1986).

Os colchões, travesseiros e almofadas apresentam-se como os melhores locais para o desenvolvimento destes ácaros, destacando-se o colchão, onde o corpo do homem fornece um microambiente ideal, com condições de temperatura, umidade relativa proveniente da transpiração e nutricionais por meio das escamações epidérmicas, que permitem a sobrevivência e reprodução da população de ácaros. Fatores como a temperatura e a umidade relativa são os principais responsáveis pela sua proliferação em determinadas regiões geográficas. Estudos indicam que $100 \%$ da mortalidade de ácaros adultos podem ocorrer com 4 a 11 dias em umidade relativa (UR) abaixo de $40 \%$ e temperaturas abaixo de $25^{\circ} \mathrm{C}$ (GUIMARÃES, 1998).

O conhecimento da fauna acarina pode melhorar os meios de investigação entre a associação e a exposição do alérgeno, podendo assim estabelecer a inclusão de novos extratos de ácaros em testes cutâneos para pacientes com alergia respiratória (SOPELETE et al., 2000; TERRA et al., 2004). 
O reconhecimento das espécies de ácaros de poeira domiciliar proporciona um avanço no conhecimento dos possíveis alérgenos da cidade, e, além disso, permite a realização de testes cutâneos mais específicos e diagnósticos mais precisos das alterações atópicas que acometem as vias respiratórias, facilitando o tratamento de ambos e melhorando a qualidade de vida do portador da alergia (MEDEIROS JÚNIOR et al., 1997).

O presente estudo teve como objetivo caracterizar as residências, com relação às suas características intrínsecas, como tipo de construção, idade, e às extrínsecas, como número de moradores, presença de animais, tipo de limpeza, temperatura e umidade relativa, dentre outros; além de caracterizar o microambiente que os ácaros de poeira domiciliar se encontram.

\section{MATERIAL E MÉTODOS}

Na cidade de Ituverava, situada no nordeste do Estado de São Paulo, com latitude de $20^{\circ} 20^{\prime} 22^{\prime \prime}$ sul, longitude 47\%46'50" oeste e a $631 \mathrm{~m}$ de altitude foram coletadas, durante o verão, em 40 residências, amostras de poeira domiciliar de sofá, cama de casal e cama de solteiro.

A seleção das residências foi feita de forma aleatória para que a amostragem correspondesse à real população dos ácaros de poeira domiciliar ocorrida nesta cidade. Os moradores das residências que concordaram em participar do estudo assinaram um Termo de Consentimento Livre e Esclarecido autorizando a coleta da poeira e responderam ao questionário a respeito das características das residências e dos seus ambientes tais como, idade da casa, tempo de moradia, tipo de construção, tipo de piso nos diferentes cômodos, número total de moradores (adultos e menores de 14 anos), apresentação de sintomas alérgicos por algum morador, presença de animais e umidade nas paredes dos cômodos. Além disso, foram coletadas amostras de poeira na sala e nos quartos e nestes cômodos, foram observadas e questionadas aos moradores as características específicas como o tipo de piso, o tipo e freqüência de limpeza utilizada, a existência de tapetes, cortinas, poltronas, almofadas e brinquedos de pelúcia.

Os sofás, as camas de casal e solteiro constituíram os microambientes nos quais foram coletadas as amostras de poeira domiciliar. Nos sofás, as características observadas foram - o tipo de sofá, o número de sofás, tipo de revestimento, tempo de uso, tipo e frequiência de limpeza, sendo que se coletava amostras de poeira de todos os sofás presentes.

Com relação às camas de casal e solteiro, foram observadas as seguintes características - material de fabricação da cama, tipo de estrado, tempo de uso da cama, tempo de uso do colchão, tipo de colchão, uso de protetores no colchão, tipo de roupa de cama e 
cobertores utilizados, e o tipo e a freqüência de limpeza utilizada no colchão, nos protetores e na roupa de cama.

Os sofás, as camas de casal e solteiro constituíram os microambientes nos quais foram coletadas as amostras de poeira domiciliar. Através da aspiração dos estofados e colchões durante cinco minutos por toda a sua superfície, utilizando aspirador de pó portátil marca Electrolux (modelo 1300, 250W), ao qual foi acoplado um filtro de papel em sua porção intermediária (marca Jovetta), onde a poeira ficou retida. Estes filtros foram dobrados, identificados, embalados em sacos plásticos e estocados em freezer a $-20^{\circ} \mathrm{C}$ para posterior análise, sem comprometimento dos possíveis ácaros existentes nas poeiras.

Ao trocar de um microambiente para outro, para fazer a aspiração, o tubo coletor do aspirador era lavado com água corrente, detergente e álcool etílico absoluto, sendo seco com papel absorvente.

No momento da coleta de poeira domiciliar foram aferidas a temperatura ambiente e a umidade relativa do ar, utilizando-se termohigrômetro (Hygrotherm, TFA, Alemanha).

\section{RESULTADOS}

Dentre as características observadas nas residências, o tipo de construção foi alvenaria em $40(100,00 \%)$, a idade da residência foi maior que 10 anos em $27(60,00 \%)$ e o tempo de moradia foi superior a 10 anos em $23(57,50 \%)$.

O piso predominante nas residências foi cerâmica com $71(65,14 \%)$, seguido de vermelhão com $19(17,43 \%)$ e taco de madeira com $13(11,93 \%)$.

O tipo de limpeza predominante nas residências foi varredura e passagem de pano úmido em 63 (57,80\%) e apenas passagem de pano úmido em 26 (23,85\%).

A frequência de limpeza que predominou nos domicílios foi a semanal em 41 (37,61\%), diária em $33(30,28 \%)$ e 2 vezes por semana em $21(19,27 \%)$.

Com relação a sinais de infiltração nas paredes, observou-se umidade nas paredes em $8(20,00 \%)$ casas.

Em $37(92,50 \%)$ residências o número de moradores foi de até 5 pessoas, sendo que em $25(62,50 \%)$ algum morador apresentava sintomas alérgicos e em 13 (32,50\%) residências foram encontrados moradores com idade inferior a 14 anos.

A presença de animais foi verificada em 23 (57,50\%) casas, sendo as espécies mais freqüentes cães, gatos, pássaros e galinhas, sendo que em 10 (43,40\%) residências estes animais tinham acesso ao interior da casa. 
Em todos os ambientes nos quais foram coletadas as amostras de poeira domiciliar, aferiu-se a temperatura e a umidade relativa que estão representadas na Tabela 1.

Tabela 1 - Valores de temperatura (T) e umidade relativa (UR), expressos em mediana, nos ambientes das residências em que foram coletadas as amostras de poeira domiciliar na cidade de Ituverava/SP, durante o período de fevereiro a março de 2005

\begin{tabular}{lll}
\hline Ambientes & Umidade Relativa $(\%)$ & Temperatura $\left({ }^{\circ} \mathrm{C}\right)$ \\
\hline Sala & 59,00 & 30,00 \\
Quarto de Casal & 64,00 & 30,00 \\
Quarto de Solteiro & 63,00 & 29,50 \\
\hline
\end{tabular}

Das 40 salas visitadas, nas quais se coletou a poeira, em $11(27,50 \%)$ havia presença somente de cortina, em 14 (35,00\%) de tapete e cortina, em 4 (10,00\%) apenas com presença de tapete e em $11(27,50 \%)$ não havia presença nem de cortina, nem de tapete. Em 8 (20,00\%) residências observou-se sinais de umidade na sala.

Nas $40(100 \%)$ residências visitadas, observou-se que 31 (77,50\%) tinham quarto de casal. Dentre as $31(100 \%), 8(25,80 \%)$ apresentaram presença de tapetes e cortinas no quarto, $2(6,50 \%)$ apresentaram apenas cortina, $1(3,20 \%)$ apresentava somente tapete e $20(64,50 \%)$ não apresentava nem tapete, nem cortina. Observou-se que todos os $31(100,00 \%)$ quartos tinham ambiente arejado e em $2(6,50 \%)$ foi observada a presença de umidade nas paredes.

Em $40(100 \%)$ residências visitadas, observou-se que 38 (95,00\%) tinham quartos de solteiro. Em $23(60,50 \%)$ quartos de solteiro não havia presença de tapete, nem de cortina, em $8(21,10 \%)$ havia presença apenas de cortina e em $7(18,40 \%)$ havia presença somente de tapete. Verificou-se que em $37(97,40 \%)$ quartos de solteiro, os ambientes apresentaram-se arejados, em $34(89,47 \%)$ não houve presença de sinais de umidade e em 12 (31,60\%) observou-se brinquedos de pelúcia.

Os sofás, em sua maioria, eram constituídos por um conjunto de 2 e 3 lugares em 25 $(62,50 \%)$ residências, seguido pelo de 2 e 3 lugares, com poltrona em 11 (27,50\%). O tipo de revestimento observado foi tecido em $29(72,50 \%)$ sofás e material sintético impermeável em $11(27,50 \%)$, e o tipo predominante foi o de madeira, com espuma e mola em $38(95,00 \%)$ casas. Foram analisadas amostras de 29 sofás, sendo que nos demais a quantidade de poeira não foi suficiente para análise.

O tempo de utilização dos sofás foi inferior a 10 anos em $32(80,00 \%)$ residências e a frequência de limpeza realizada nestes era semanalmente em 20 (50,00\%), diariamente em 6 $(15,00 \%)$ e em $2(7,50 \%)$ eram feitas 2 vezes por semana, sendo o método de limpeza 
mais utilizado a passagem de pano úmido em 11 (27,50\%) e pano úmido com produtos de limpeza específicos $6(15,00 \%)$ residências.

Nos sofás foram encontrados 1.012 (100\%) ácaros/g de poeira, sendo que o que apareceu com maior frequência foi o gênero Dermatophagoides, com 714 (70,56\%) ácaros/g de poeira.

De um total de 31 (100\%) camas de casal, 30 (96,80\%) eram de madeira, sendo todas com estrado de madeira vazado. O tempo de uso das camas foi inferior a 10 anos em 13 $(41,90 \%)$ casas. O tipo de colchão predominante foi de espuma em $27(87,10 \%)$ camas de casal e o tempo de uso do colchão foi inferior a 10 anos em 23 (45,20\%). Em 16 (51,60\%) colchões havia uso de protetores.

O tipo de limpeza mais frequente dos colchões foi a sua exposição ao sol em 17 $(54,80 \%)$ casas, sendo que em 9 (29,00\%) nenhum tipo de limpeza era dispensado aos colchões, ou era utilizado pano úmido 1 (3,20\%), lavagem 1 (3,20\%), espanação $2(6,50 \%)$ e aspiração $1(3,20 \%)$. A freqüência de limpeza no colchão foi de uma vez por ano em 5 (16,10\%) ou de 6 em 6 meses em 5 (16,10\%), seguido de semanal em 4 (12,90\%), 2 vezes por mês em $3(9,70 \%), 2$ em 2 meses $3(9,70 \%)$ e 3 em 3 meses em $2(6,50 \%)$.

O tipo de roupa de cama mais utilizada foi de algodão em $25(80,60 \%)$ colchões, tendo sua frequência de limpeza predominante a semanal 20 (64,50\%), utilizando-se água e sabão em $30(96,80 \%)$.

Nas amostras de poeira da cama de casal foi encontrado um total de 2.982 ácaros/g de poeira, sendo o que apareceu com maior frequência, foi o gênero Dermatophagoides 1.758 (58,96\%), a espécie Dermatophagoides farinae com 1.126 (37,76\%), Dermatophagoides evansi (Figura 14) 174 (5,83\%) e Euroglyphus maynei com 108 (3,63\%)

De um total de 47 (100\%) camas de solteiro, todas tinham estrado de madeira vazado e $44(93,60 \%)$ eram de madeira, sendo as outras $3(6,40 \%)$ de material metálico. O tempo de uso da cama foi inferior a 10 anos em $22(46,80 \%)$ residências.

O tipo predominante de colchões de solteiro foi de mola e espuma em $44(93,60 \%)$ e o tempo de uso destes foi inferior a 10 anos em $36(76,60 \%)$.

Em $30(63,70 \%)$ das camas de solteiro havia o uso de protetores no colchão.

Nos colchões de solteiro não foi dispensado nenhum tipo de limpeza em 24 (51,10\%) e a sua exposição ao sol em $22(46,80 \%)$, e lavagem em 1 (2,10\%). A frequiência de limpeza desses colchões era semestral em 6 (12,80\%), mensal em 5 (10,60\%), semanal em 4 (8,50\%), de 2 em 2 meses em 4 (8,50\%), 3 vezes por ano em 2 (4,30\%) e anual em 2 (4,30\%), sendo que a maioria $24(51,10 \%)$ não apresentou nenhuma freqüência de limpeza. 
A roupa de cama mais utilizada foi do tipo algodão em $45(95,70 \%)$ colchões de solteiro, tendo, em sua maioria, a frequência de limpeza semanal em $32(68,10 \%)$, utilizandose água e sabão neutro em $45(95,74 \%)$ roupas de cama. Foram encontrados ácaros de poeira domiciliar em todos os microambientes avaliados.

Em camas de solteiro a quantidade total de ácaros encontrados foi de 5.112 ácaros/g de poeira, sendo que apareceu com maior frequência, foi o gênero Dermatophagoides 2.762 (54,03\%), a espécie Dermatophagoides farinae com 1.666 (32,59\%), Euroglyphus maynei $352(6,89 \%)$ e Dermatophagoides pteronyssinus com $52(1,02 \%)$

\section{DISCUSSÃO}

Os ácaros de poeira domiciliar foram encontrados em todas as residências estudadas e o microambiente em que se encontrou maior frequência de ácaros foi a cama de solteiro, provavelmente devido à presença de fatores nutricionais e climáticos favoráveis ao crescimento e proliferação desses microrganismos. Segundo Wickens et al. (1997) os altos níveis de ácaros em poeira domiciliar é devido a uma variedade do estilo de vida e fatores climáticos, além de se observar que famílias com maior número de crianças e de classe social inferior possui um número maior de ácaros nas camas de solteiro, provavelmente devido aos diferentes comportamentos de limpeza e de acordo com Custovic (1996) a idade do colchão não interfere na quantidade de ácaros encontrados.

$\mathrm{Na}$ cidade de Ituverava/SP a temperatura e a umidade relativa podem ter influenciado na prevalência da espécie $D$. farinae, já que a condição climática do ambiente domiciliar interfere no número e na variedade de ácaros encontrados (EZEQUIEL et al., 2001).

$\mathrm{Na}$ análise das correlações entre frequência de limpeza do ambiente, frequência de limpeza do microambiente, temperatura, umidade relativa e quantidade de ácaro por grama de poeira não terem sido significativas, demonstra que estes fatores não atuam isoladamente, assim, a frequência de ácaros deve estar sob a influência de todos esses fatores e de outros intrínsecos ao microambiente. Segundo Ree et al. (1997), a frequência de limpeza foi comparada com o número de ácaros encontrados e, não houve correlação estatística entre eles.

\section{CONCLUSÃO}

As casas de alvenaria, acima de 10 anos, com piso de cerâmica foram as mais relatadas no estudo.

A frequência de limpeza semanal utilizando varredura e pano úmido foi a mais utilizada nos ambientes domiciliares. 
O microambiente com maior número de ácaros por grama de poeira foi na cama de solteiro.

A frequência de limpeza nos microambientes requer mais cuidados, principalmente em residências com moradores portadores de alergia.

\section{REFERÊNCIAS}

BAGGIO, D. Ácaros da poeira domiciliar e alergia. In: SEMINÁRIOS SOBRE INSETOS E ÁCAROS. Anais... 3. Campinas: Sociedade Entomológica do Brasil Fundação Cargil, 185p. p.173-185, 1989.

CUSTOVIC, A. et al. New mattresses: how fast do they become a significant source of exposure to house dust mite allergens? Clinical and Experimental Allergy, v. 26, n. 11, p. 1225-1227, Nov. 1996.

EZEQUIEL, O. DA S. et al. Evaluation of the acaro fauna of the domiciliary ecosystem in Juiz de Fora, State of Minas Gerais, Brazil. Memórias do Instituto Oswaldo Cruz, v. 96, n. 7, p. 911-916, Out. 2001.

FLECHTMANN, C. Ácaros em produtos armazenados e na poeira domiciliar. Piracicaba: FEALQ, 97p., 1986.

GELL, P. H. G.; COOMBS, R. R. A. Classification of allergic reactions responsible for clinical hypersensitive and disease. In: GELL, P. H. G.; COOMBS, R. R. A.; LACHMANN, P. J. Clinical Aspects of Immunology, 3 ed. London. 1975. Cap. 25

GUIMARÃES, K. S. Identificação de ácaros da poeira domiciliar na cidade de SalvadorBA: Estudo preliminar. 1998. 52f. Trabalho de Conclusão de Curso (Graduação em Ciências Biológicas). Universidade Federal da Bahia. Salvador.

MEDEIROS JÚNIOR, M. Sensibilização a aeroalérgenos em indivíduos portadores de asma brônquica e/ou rinite crônica em Salvador-Bahia. 1997. 71f. Dissertação (Mestrado em Medicina) Universidade Federal da Bahia. Salvador.

REE, H. I.E et al. Fauna and geographical distribution of house dust mites in Korea. The Korean journal of parasitology. V. 35, n.1, p. 9-17, 1997.

SOPELETE, M. C.et al. Dermatophagoides farinae (Der f 1) and Dermatophagoides pteronyssinus (Der p 1) allergen exposure among subjects living in Uberlândia, Brazil. International Archives of Allergy and Immunology, v. 122, n. 4, p. 257-263, Ago. 2000.

TAKETOMI, E. A., SOUZA, G. G. Exposição a alérgenos inalantes domiciliares entre pacientes asmáticos de Uberlândia-MG. 1998. 35f. Relatório final para o CNPQ. Universidade Federal de Uberlândia.

TERRA, S. A. et al. Mite allergen levels and acarologic analysis in house dust samples in Uberaba, Brazil. Journal of Investigational Allergology and Clinical Immunology.v.14, n. 3, p. 232-237, 2004.

WICKENS, K. et al..Determinants of house dust mites allergen in homes in Wellington, New Zealand. Clinical and Experimental Allergy v. 27, n. 9, p. 1077-1085, set. 1997. 